American Journal of Environmental Sciences 5 (4): 501-507, 2009

ISSN 1553-345X

(C) 2009 Science Publications

\title{
Rocks with Asbestos: Risk Evaluation by Means of an Abrasion Test
}

\author{
Bellopede Rossana, Clerici Carlo, Marini Paola and Zanetti Giovanna \\ DITAG-Department of Land, Environment and Geo-Engineering, Politecnico di Torino, \\ Corso Duca Degli Abruzzi 24, 10129 Torino, Italy
}

\begin{abstract}
Naturally occurring asbestos and asbestiform minerals can be found in metamorphic rocks and in the soil of the alluvial plains. Problem statement: The definition of the "free-asbestos rock" and the limit to consider a rock or a soil safe is still a controversial issue. American and European laws did not present any method to define the hazard of the green stones, instead Italian law, in Ministerial Decree1996, established a limit value obtaoined by the determination of the Release Index. In order to detect an asbestos concentration in the rocks, a reliable analytic methodology has been necessary. Approach: An abrasion trial, using the mechanism action of a rotary cylinder, and a Phase Contrast Optical Microscopy (PCOM) method to analyze the powder obtained from the mill, had been used. To simplify PCOM analysis, the sample, recovered from the mill, was selected in particle size classes: large, medium and small. Each class was separated by means of sedimentation in fibrous and granular fractions. Results: The separation of asbestos in large and medium classes was quite good and the fibers had been weighed. For the small class the transformation of visible data into numerical data was complex, but the results had been reliable. Conclusion/Recommendations: The suggested method, although semi-quantitative, could be useful to solve the difficult problem of the analysis of the asbestos content in the rocks or soils. The division into granular classes allowed a more representative sample to be analyzed and better quality slides to be prepared. From the results obtained, the analysis of the small classes by means of PCOM was a critical point: The use of the SEM method can improve it.
\end{abstract}

Key words: Asbestiform minerals, hazard, release index, PCOM

\section{INTRODUCTION}

In mineralogy, the term "asbestiform" is used to describe the specific crystal habit in polyfilamentous fibers organized in bundles, while the term "Asbestos" indicates a group of six minerals (Chrysotile, Tremolite, Actinolite, Antophyllite, Crocidolite and Amosite Table 1) which have the same fibrous crystalline habit and the similar properties like flexibility, high tensile strength, long shape, high mechanical thermal stability, low thermal and electrical conductivity, high absorbency and resistance to acid and bases. Due to these characteristics the asbestos minerals, already used since Romans for their resistance to fire, became from the 19th century very important as industrial minerals ${ }^{[1]}$.

The asbestos bearing lithogies are metamorphosed mafic and ultra mafic rocks and more rarely metamorphosed carbonate rocks, in Fe-cherts and ironstones ${ }^{[2,3]}$. The asbestos of amphibole is less common than chrysotile, they can be present in the same rocks as serpentine asbestos and all these fibrous minerals may occur in slip-fiber and cross-fiber veins and as mass fiber deposits.

\begin{tabular}{|c|c|c|c|}
\hline $\begin{array}{l}\text { Regulatory } \\
\text { name }\end{array}$ & $\begin{array}{l}\text { Non fibrous } \\
\text { mineral variety }\end{array}$ & $\begin{array}{l}\text { Mineral } \\
\text { group }\end{array}$ & Formula \\
\hline Chrysotile & $\begin{array}{l}\text { Antigorite and } \\
\text { lizardite }\end{array}$ & Serpentine & $\mathrm{Mg}_{3} \mathrm{Si}_{2} \mathrm{O}_{5}(\mathrm{OH})_{4}$ \\
\hline Crocidolite & Riebekite & Amphibole & $\mathrm{Na}_{2}\left(\mathrm{Fe}^{2+}{ }_{3}, \mathrm{Fe}^{3+}{ }_{2}\right) \mathrm{Si}_{8} \mathrm{O}_{22}(\mathrm{OH})_{2}$ \\
\hline Tremolite & Tremolite & Amphibole & $\mathrm{Ca}_{2}(\mathrm{Mg}, \mathrm{Fe})_{5} \mathrm{Si}_{8} \mathrm{O}_{22}(\mathrm{OH})_{2}$ \\
\hline Actinolite & Actinolite & Amphibole & $\mathrm{Ca}_{2}\left(\mathrm{Mg}, \mathrm{Fe}^{2+}\right)_{5} \mathrm{Si}_{8} \mathrm{O}_{22}(\mathrm{OH}, \mathrm{F})_{2}$ \\
\hline Antophyllite & Antophyllite & Amphibole & $(\mathrm{Mg}, \mathrm{Fe})_{7} \mathrm{Si}_{8} \mathrm{O}_{22}(\mathrm{OH})_{2}$ \\
\hline Amosite & $\begin{array}{l}\text { Cummingtonite- } \\
\text { Grunerite }\end{array}$ & Amphibole & $\mathrm{Mg}_{2} \mathrm{Fe}^{2+}{ }_{5} \mathrm{Si}_{8} \mathrm{O}_{22}(\mathrm{OH})_{2}$ \\
\hline
\end{tabular}

Many other minerals, such as attapulgite, balangeroite, carlosturanite, erionite, brucite, fluoroedenite, palygorskite, sepiolite, wollanstonite and others can show the asbestiform habit in specifc crystallization conditions, but we can find information on their risk hazard only when, as in the case of Fluoroedenite of Biancavilla (Fig. 1 and 2), an effective link between the presence of the mineral and the increase of mortality has been found ${ }^{[4]}$.

Naturally occurring asbestos and asbestiform minerals can be found also in the soil of the alluvial plain that can be moved and transported far from the place of origin.

Corresponding Author: Paola Marini, DITAG-Department of Land, Environment and Geo-Engineering, Politecnico di Torino, Corso Duca Degli Abruzzi 24, 10129 Torino, Italy Tel: 011-0907625 Fax: 011-0907699 


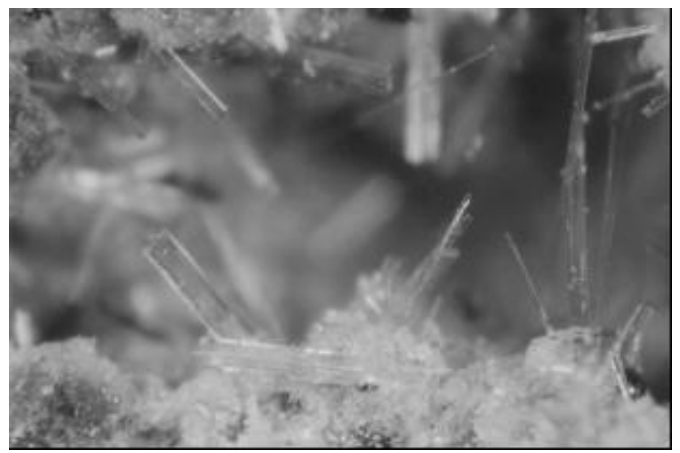

Fig. 1: Fluoroedenite in a rock micro-cavity ${ }^{[5]}$. Short side of photograph is $1.1 \mathrm{~mm}$

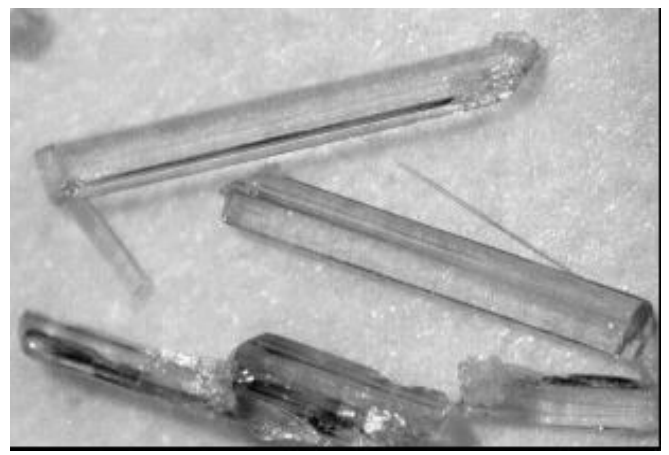

Fig. 2: Fluoroedenite fibers ${ }^{[5]}$. Short side of photograph is $1.1 \mathrm{~mm}$

There are divergences among the researchers in the definition of fibers: Should only be considered fibers or the acyclic or the squat prism from cleavage? What do the words "free-asbestos rocks" mean? The answer could be: "free-asbestos rock" is a natural material where asbestos is not detectable by means of a definite analytic methodology. Which is the limit to consider a rock or a soil safe: $<1 \%$ or $<1 \mathrm{mg} \mathrm{ton}^{-1}$ ?

In order to detect an asbestos concentration in the rocks, a reliable analytic methodology is necessary, above all for very low concentrations. In this kind of analysis, sampling plays a fundamental role, both in situ, because of the distribution of asbestos in the rocks, which is often very heterogeneous and changeable and in laboratory, because of the very different spatial distribution of fibers in the sample, even reduced in small size after milling.

Finally, it should be taken into account another specificity of the naturally occurring asbestos: The rocks or soils with asbestos can be subject to different processes such as construction of roads, foundations, earth moving and so on, but actually laws or regulations are still deficient ${ }^{[5,6]}$.
International and European laws and regulations on naturally occurring asbestos: Regulations on asbestos in the USA initially resulted from concern over the health and safety of workers subject to occupational exposure to asbestos. The NIOSH (National Institute for Occupational Safety and Health), encompassed minerals according to the crystalline structure and elemental composition of the asbestos varieties (crocidolite, crysotile, amosite, anthophyllite asbestos, tremolite asbestos and actinolite asbestos). It also includes the non asbestiform varieties of the asbestos minerals (antigorite and lizardite serpentine minerals and the amphibole minerals of the cummingtonitegrunerite mineral series, the tremolite-ferroactinolite mineral series and the glaucophane-riebeckite mineral series).

In California, regulations have been implemented to protect the public from exposure to naturally occurring asbestos. The California Air Resources Board (CARB) has identified the following minerals as asbestos (in the asbestiform habit): Chrysotile, crocidolite, amosite, fibrous tremolite, fibrous actinolite and fibrous anthophyllite as a toxic air contaminant $^{[7]}$. In doing so, CARB identified all asbestos fibers, irrespective of their length, with an aspect ratio greater than or equal to $3: 1$, equally hazardous to public health. Since 1990, CARB adopted an asbestos Airborne Toxic Control Measure (ATCM). Actually ATCM restricted the use of serpentine and ultramafic rock aggregates for surfacing applications, to materials containing less than $0,25 \%$ asbestos determined according to CARB Method 435. In July 2001, the CARB adopted an additional asbestos ATCM for construction, grading, quarrying and surface mining operations ${ }^{[7]}$.

In the International environment, with reference to airborne free asbestos fibers, the following limit values have been required:

100 fibers/l (by means of Phase Contrast Optical Microscopy): Threshold Limit Value (TLV) for exposition to asbestos in the work environment established by $\mathrm{ACGIH}^{[8]}$.

1 fiber/l (by means of SEM) for non professional exposition to asbestos: Indicated by $\mathrm{WHO}^{[9]}$. These ranges were proposed with a view to providing adequate health protection, but their validity is difficult to judge.

In European environment, there are no accurate directives on naturally occurring asbestos, while the regulation on the prohibition of employment and production of articles with asbestos are even more restricted. The most recent regulation is Commission Directive 1999/77/EC of 26 July 1999 relating to 
restrictions on the marketing and use of dangerous substances and preparations (asbestos).

The Commission Directive 2003/18/EC sets the limit of 100 fibers/l as the indication of ACGIH and confirms the six fibrous asbestos of the NIOSH. The European Directives don't consider the risk connected to activities such as quarrying, manipulation or construction with rocks containing asbestos; in other words it is possible to use the rock with asbestos in Europe, within safety conditions ${ }^{[10]}$.

In Italy, Law 257/92 deals with the cessation of asbestos employment. It concerns materials with asbestos and in art. 12 classifies waste with asbestos as being special, toxic and noxious according to properties that reveal their hazard risk such as friability and density; these two parameters are used to defined the release index for the waste. In M.D. 14/05/96 the hazard risk of "green stones" is evaluated through the Release Index (ratio of concentration of liberated asbestos after abrasion tests and relative density).

In Italy the first law, that governs the protection of workers L. 277/91, lists the asbestos minerals (crysotile, crocidolite, amosite, tremolite actinolite, anthophyllite). This classification has not been modified by the subsequent laws.

As far as the problem to the naturally occurring asbestos, in Italy the mapping of asbestos occurring areas, foreseen by M.D. 18/03/2003 n. 101 is in progress ${ }^{[11]}$.

From the Sanitary point of view the riskiness of asbestos is linked to the fiber shape: breathable fibers have diameters $<3 \mu \mathrm{m}$, length $>5 \mu \mathrm{m}$ and $1 / \mathrm{d}>3$.

The abrasion test on rocks with asbestos: The abrasion test methodology is performed according the Italian Ministerial Decree 14.05.96. This test is, broadly speaking, an autogenous-milling.

In particular, the Italian decree suggests for stone fragments a size of $5-50 \mathrm{~mm}$ and weight of $0,5 \mathrm{~kg}$; the apparatus is a steel rotary cylinder with a diameter of $300 \mathrm{~mm}$, an axial length of $400 \mathrm{~mm}$ and a rotation speed of $50 \mathrm{rpm}$; the self-milling duration is of $4 \mathrm{~h}$.

An important factor in the self-milling test is the "critical speed", that is, the lowest rotary speed where a grain inside the cylinder sticks to internal wall (this is verified when the centrifugal force is equal to its weight).

The rotary speed in the abrasion tests is lower than the "critical speed". From the point of view of mechanical action strength, there are two kinds of movements: cascading rotation for rotary speeds lower than $40 \%$ critical speed (Fig. 3a); cataracting rotation for rotary speeds of between $50 \%$ and $90 \%$ critical speed (Fig. 3b).
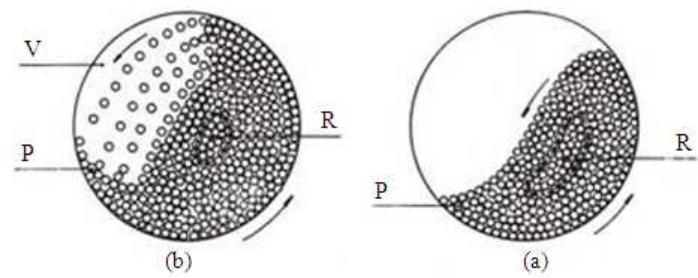

Fig. 3: Cascading (a) and cataracting (b) movement in a rotary cylinder partially filled with grains

As far as the cascading movement is concerned, the rock fragments roll one on top of another, without falling; the mechanical action is essentially an abrasion of the surface of the rock fragments.

As far as the cataracting movement is concerned, the rock fragments rise higher inside the cylinder and fall away from the interior walls in a parabolic way; therefore there is an impact of the falling together with abrasion of the surfaces (due to the rotation); the mechanical action become stronger and stronger and the pulverizing is very effective; the comminution is most effective for rotary speed of between 75 and $85 \%$ of critical speed.

Considering that the rotary speed of $50 \mathrm{rpm}$, required by Italian M.D., is equal to $59-64 \%$ of the critical rotary speed, that is a cataracting rotation but does not correspond to the maximum of the mechanical strength.

The asbestos Release Index (RI) is a ratio between the percentage of liberated asbestos from the mill and its relative density $\%$ and, according to Italian M.D. $14 / 05 / 96$ it should be minor less 0.1 to define a material as "not hazardous".

Analytical methods to determine the amount of asbestos: The analytical methods used to study massive samples are: X-ray diffraction, infra-red adsorption spectroscopy, PCOM and SEM (TEM is less frequently used in Italy).

These methods offer different performances. The most important differences concern the influence of the matrix on the analytical answer, the mass of the analytical sample, the detection limit (that is, the lowest concentration measurable) and the precision of the quantitative analysis.

$\mathrm{X}$-ray diffraction and infra-red adsorption spectroscopy can't distinguish between fibrous and non-fibrous forms of the same sample (for example between antigorite and chrysotile). In the analysis of handmade materials this mistake has little influence on the result, since the used asbestos is purified from the granular rocky fraction. Instead in rock analysis, where 
non-fibrous forms are surely present, the mistake can be of great importance.

X-ray diffraction studies samples of around 500$1000 \mathrm{mg}$, while infra-red adsorption spectroscopy examines samples of around 2-3 mg. In the microscopic methods the mass of the sample on the slide or stub is about a fraction of $\mathrm{mg}$ or at most a few mg. However the method based on PCOM used in the laboratory of Politecnico di Torino (DITAG) involves the division of the starting sample (with mass of around 50-100 g) into particle size classes by wet sieving, then each class is observed under the microscope. In this way, the amount of analyzed sample, divided into granular fractions, is more representative.

The detection limit for X-ray diffraction and infrared adsorption spectroscopy is about $0.5 \%$. This means that the signal is not discernible for small amounts from that of the matrix without asbestos. Microscopic methods, instead, can sense even a very few contents. For example, the finding of some fibers of $1 \mu \mathrm{m}$ of diameter and with a whole mass of some pico-grams on a slide of $0.5 \mathrm{mg}$ (normal value for optical microscope slide) means an amount of asbestos of about $0.01 \%$.

Microscopic methods are sure and reliable for the qualitative analysis (recognizing the nature of a singular particle: asbestos or non asbestos), but they have objective difficulties in transforming visible data into numerical data. Therefore, microscopic methods should be considered semi-quantitative analyze. X-ray diffraction and infra-red adsorption spectroscopy does not suffer from this problem because they are based on the comparison of sample signals with the standard reference.

The influence of the matrix is the most important reason for mistakes in asbestos rock analysis. Therefore, microscopic methods are more suitable. In order to compare the performances of optical and electrical microscopy, DITAG is at present carrying out an experimentation with two ARPA laboratories (Milano and Reggio Emilia). The results of the experimentation in optical microscopy conducted at the DITAG laboratory are shown hereafter.

\section{MATERIALS AND METHODS}

The experiments were carried out using: cellulose nitrate membrane $0.8 \mu \mathrm{m}$ pore size, $47 \mathrm{~mm}$ diameter, filter for quantitative analysis and Acetone-triacetin.

The main instruments used were a microscope with positive phase contrast , $5 \mathrm{X}, 10 \mathrm{X}, 40 \mathrm{X}$ objective, a diaphanizator and a mill characterized by dimensions defined according to Italian M.D. 14/05/96.
The procedure begins with the milling of the breccia material in tests conducted according to aforementioned Italian M.D. 14/05/96.

The material has to be extracted from the mill and accurately washed using water at room temperature. The mill is also washed accurately to recover the remaining material that has to be measured. The breccia material is then dried and put away.

The powder material is divided by sieves of different dimensions in order to select the powder according to different particle size classes: Large (0.6 or $0.3 \mathrm{~mm})$, medium $(0.075$ or $0.050 \mathrm{~mm})$ and small (less than 0.075 or $0.050 \mathrm{~mm}$ ). This selection was conceived to facilitate the optical microscope examination and it is carried out by washing the powder on each sieve with water. The dimension of the sieve is selected according to the particle size of the powder recovered from the mill.

Each class is separated in two fractions: Granular and fibrous fraction with a sedimentation method, in order to simplify the analysis.

The specimen, recovered from the sieve, is put in a Becker with $200 \mathrm{~mL}$ of water and it is shaken using a mechanical shaker (Fig. 4).

This opens the chrysotile fibers, if present and they start floating (Fig. 5).

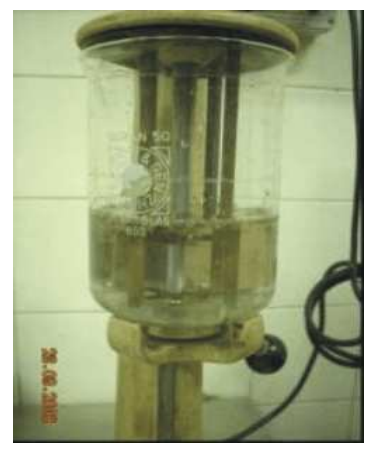

Fig. 4: Mechanical shaker

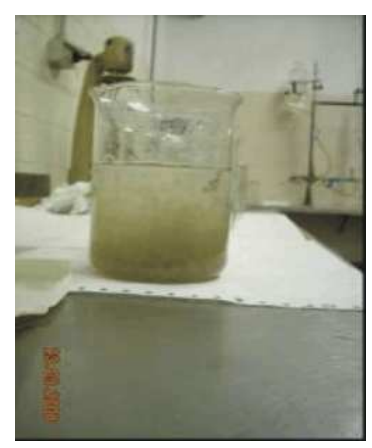

Fig. 5: Becker with floating asbestos 
Consequently, the fibers can be recovered through filtering which is carried out using a vacuum pump equipped with a nitrate of cellulose membrane. The choice of this kind of membrane is advantageous and even mandatory, due to the fact that it does not deliver organic fibers and it may be diaphanized. The fiber suspension procedure has to be repeated until no more fibers can be seen by the analyst.

The two fractions obtained for each class are analyzed with the PCOM in order to evaluate the success of the separation. The slides are prepared with liquid of different refractive indexes in order to recognize the asbestos fibers: 1.550 for chrysotile, 1.565 for antigorite, 1.610 for tremolite.

The powder recovered from the sieve is filtered using a quantitative analysis filter and is then dried. The powder is recovered and disaggregated using a porcelain mortar. A quote of $0.1 \mathrm{mg}$ is suspended in $10 \mathrm{~mL}$ water and put in a ultrasonic bath for $15 \mathrm{~min}$. Then, the solution is filtered using a $47 \mathrm{~mm}$ cellulose nitrate filter in order to obtain a regular dispersion. The filter is subsequently diaphanized and tested in PCOM.

The asbestos quantity of the large class may be calculated from the direct weight of the fibrous fraction, while that of the intermediate class is obtained by weighing the fibrous fraction and correcting the value after the optical evaluation of the pollution of pebbles.

The asbestos quantity of the small class is calculated observing the cellulose-nitrate membrane with a PCOM. Each fiber observed is measured in order to calculate the volume. The density of the asbestos allows us to know the weight of the fiber on the membrane, this value being related to the entire powdered area of the membrane and therefore to the amount $(0.1 \mathrm{mg})$ of powder deposited on it.

The per cent content of asbestos is obtained as the weighed mean of the different particle size classes. The results have to be considered semi-quantitative, since it is difficult to transform the number of fibers into a weight value.

\section{RESULTS}

The large class is generally well selected: The granular fraction (Fig. 6) does not show any fibers, while the fibrous fraction (Fig. 7) can present some powder and, in some case, also some pebbles.

The intermediate class shows a well selected granular fraction (Fig. 8), while the fibrous fraction (Fig. 9) is polluted by some pebbles. The pollution has been evaluated using an optical microscope.

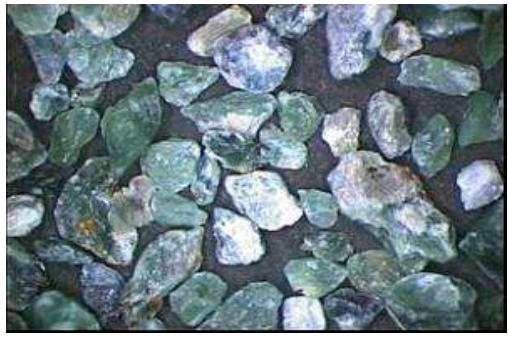

Fig. 6: Separation of the granular fraction of the large class (stereomacroscope $0.63 \mathrm{x}$ ). Short side of photograph is $15 \mathrm{~mm}$

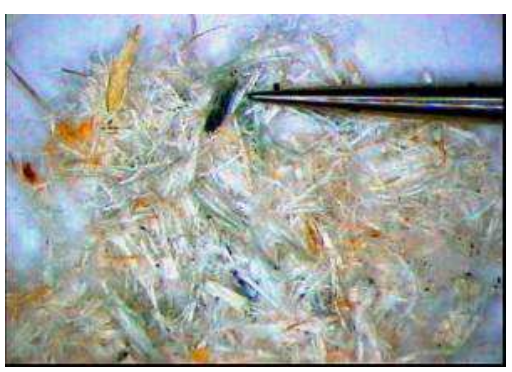

Fig. 7: Separation of the fibrous fraction of the large class (stereomacroscope $0.63 \mathrm{x}$ ). Short side of the photograph is $15 \mathrm{~mm}$

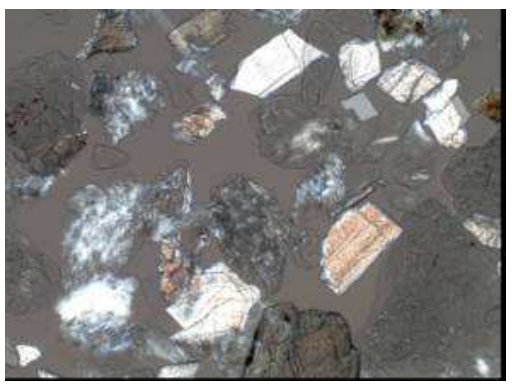

Fig. 8: Medium class, granular fraction, LP optical microscope, 10X (short side of the photograph is $940 \mu \mathrm{m})$

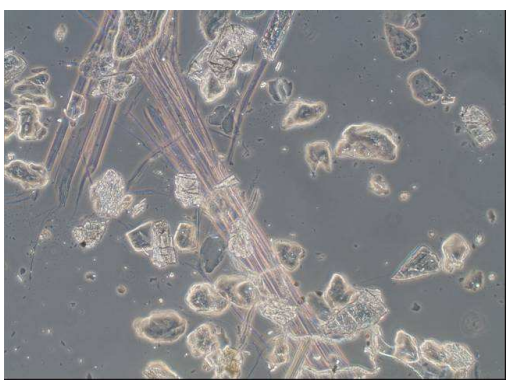

Fig. 9: Medium class, fibrous fraction, PCOM, 10X (short side of the photograph is $940 \mu \mathrm{m}$ ) 


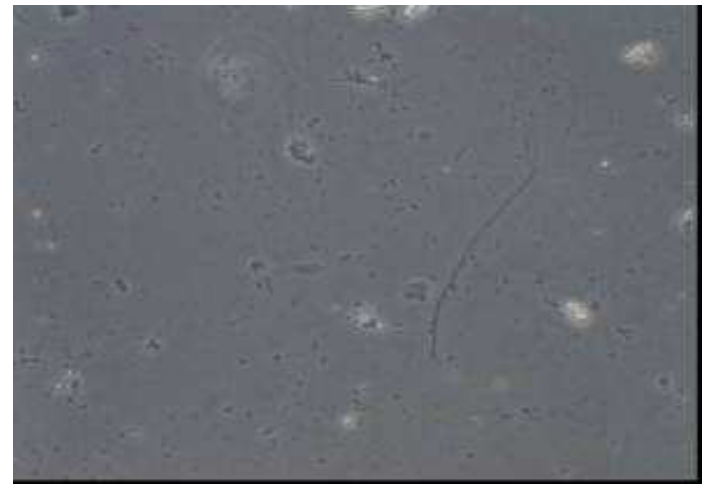

Fig. 10: Small class, PCOM, 40X, general vision of the membrane (short side of the photograph is $235 \mu \mathrm{m})$

The small class has not been separated, therefore the membrane (Fig. 10) shows some fibers and some pebbles.

\section{DISCUSSION}

The above-described method is a suggestion to solve the difficult problem of the analysis of the powder obtained from the mill.

This method consists of many steps and is therefore not simple. However, the division into granular classes allows a more representative sample (larger amount of analyzed sample) to be analyzed and better quality slides to be prepared. The asbestos is easily-recognized thanks to chromatic dispersion. Large and medium classes are divided into granular and fibrous fractions, therefore the amount of asbestos is obtained by weighing the materials and, considering the mistakes in the selection, by correcting the value with PCOM.

The critical point is the analysis of the small fraction both for the detection limit of PCOM and for the transformation of visible data into numerical data. In our opinion the obtained results are reliable, even though they could be improved using SEM to analyze the small class.

\section{CONCLUSION}

The asbestos problem, which has recently raised a big interest, presents two different aspects: The manmade materials (asbestos products) and the natural occurring asbestos.

For the first case the "zero hazard" can be reached with the removal of the handmade materials, using the right methodologies and the correct disposal of waste materials. It has to be remembered that the hazard is in relation with the density and the friability of the products; the fibers dispersion of a vinyl floor is very different from that of sprayed asbestos.

The rocks containing asbestos can be found in many areas, but the amount of asbestos is normally not so relevant, with the exception of some mines. The approach to study the problem can be the same of the handmade materials.

The soil, that presents on the surface some friable asbestos, can become safety covering with a polyethylene cloth and with other earth and grass. But what is it possible to do for asbestos rock, that contain few amount of fibers? It is not possible to say: "Don't move or touch these materials".

For these reasons it is necessary a specific law. The Index Release of Italian law is a first step in this direction and it has to be evaluated and improved.

\section{REFERENCES}

1. Ross, M., A.M. Langer, G.L. Nord, R.P. Nolan and J.R. Lee et al., 2008. The mineral nature of asbestos. Regualt. Toxicol. Pharmacol., 52: S26-S30. http://www.ncbi.nlm.nih.gov/pubmed/18423957

2. California Geological Survey, 2002. Guidelines for geologic investigations of naturally occurring asbestos in California. Special Publication 124. http://www.conservation.ca.gov/cgs/minerals/hazar dous_minerals/asbestos/Documents/Asbestos_Guid elines_SP124.pdf

3. Compagnoni, R. and C. Groppo, 2006. The asbestos in the rocks of the Susa Valley (Torino Province, Piemonte, Italy). Rendiconti Soc. Geol. Italiana, 3: 21-28.

http://cat.inist.fr/?aModele $=$ afficheN\&cpsidt $=1841$ 7753

4. Belpoggi, F. and M. Soffritti, 2007. La Fluoroedenite induce mesoteliomi peritoneali e pleurici nei ratti: Prima dimostrazione sperimentale. Convegno Nazionale Anfiboli Fibrosi: Nuove Problematiche Relative al Rischio Ambientale e Sanitario, Apr. 27-28, Rome, Italy, pp: 1-52. http://tetide.geo.uniroma1.it/dst/grafica_nuova/bac heca/Minerali_fibrosi/Presentazioni\%20Convegno \%20Roma/Pdf\%20I\%20sessione/Belpoggi.pdf

5. Bologna, L., C. Clerici and M. Wojtowicz, 2008. Rischi da materiali alternativi all'amianto e da fibre asbestiformi da fonti naturali in Italia. G. Ig. Ind., 33: 160-175.

http://www.aidii.it/allegati/indice\%20tlv\%2008.pdf 
6. Clerici, C. and M. Wojtowicz, 2006. Importanza attuale della prova di abrasione sulle "Pietre verdi" ai fini della valutazione del rischio derivante dall'amianto in natura. G. Ig. Ind. Suppl., 31: 189-209. http://www.aidii.it/allegati/TLV\%20indice $\% 20200$ 6.pdf

7. CARB Method 435, 1991. Determination of asbestos content of serpentinite aggregate. State of Air Resources Board, California. http://www.arb.ca.gov/testmeth/vol3/M_435.pdf

8. ACGIH, 2001. Documentation of the threshold limit values and biological exposure indices. http://www.acgih.org/store/ProductDetail.cfm?id=6 52

9. WHO., 2000. Air quality guidelines for Europe. WHO Regional Office Europe, Ginevra, ISBN: 9289013583, pp: 273.
10. Bonomo, F., 2008. Le cave di serpentino nell'intrico normativo. Quarry Construct. Bologna, 544: 45-51.

http://www.edizionipei.it/pdf/SOMM-QC-apr2008.pdf

11. Coraglia, B., F. Forlati, E. Fusetti, L. Giacomelli and M. Morelli et al., 2006. Naturally occurring asbestos. Mapping project: The experience of regione piemonte. Proceeding of the European Conference on Asbestos Risk and Management, Dec. 4-6, Rome, pp: 1-56. http://venus.unive.it/fall/menu/Giacomelli.pdf 